\title{
Cross-Sectional Guidelines for Therapy with Blood Components and Plasma Derivatives (4th revised edition, 2008) - Suspension of Chapter 5 'Human Albumin'
}

Due to the discovery of grave scientific misconduct $[1,2]$ by Prof. Dr J. Boldt, the co-author of the Cross-Sectional Guidelines for Therapy with Blood Components and Plasma Derivatives [3], the Scientific Advisory Board has decided to terminate its collaboration with this author with immediate effect.

In light of current knowledge, the necessity has arisen to review further publications by the same author in addition to the one involved in above-mentioned misconduct case [4], particularly those concerning the use of hydroxyethyl starch for therapeutic purposes.

Against this background, Chapter 5 'Human Albumin' of the Cross-Sectional Guidelines, which in its recommendations repeatedly refers to Prof. Dr. J. Boldt's publications, is immediately suspended. Until publication of the revised edition, differential therapeutic decisions should not be based on the treatment recommendations contained in this chapter.

This suspension has become necessary since, despite an extensive process of consensus building on the Cross-Sectional Guidelines among the members of the Permanent Working Group and the plenum of the Scientific Advisory Board as well as consultation with more than 80 scientific associations, the possibility cannot be ruled out with sufficient certainty that collaboration with and the publications of this co-author have influenced the contents of the recommendations in a potentially inappropriate manner.

The early revision and updating of Chapter 5 of the CrossSectional Guidelines by a working group of the Scientific Advisory Board has been initiated. As before, the revision process will comprise extensive consultation with relevant experts and specialist institutions.

\section{Prof. Dr. med. Dr. h.c. J.-D. Hoppe}

President of the German Medical Association and of the German Medical Assembly

\section{Prof. Dr. med. Dr. h.c. P.C. Scriba}

Chairman of the Scientific Advisory Board of the German Medical Association

\section{Prof. Dr. med. H. Klüter}

Central Coordinator of the Standing Working Group 'Guidelines for Hemotherapy'

\section{References}

1 Shafer SL: Notice of retraction. Anesth Analg 2010;111:1567.

2 Pressemitteilung des Klinikums Ludwigshafen vom 29.11.2010 zu dem Bericht der Untersuchungskommission. www.klilu.de/deutsch/news/Untersuchungsbericht-der-kommission-fuer-die-pressekonferenz-am-29-november-2010/.
3 German Medical Association - Scientific Advisory Board: Cross-Sectional Guidelines for Therapy with Blood Components and Plasma Derivatives (4th revised edition, 2008). Transfus Med Hemother 2009;36:345-492.
4 Boldt J, Suttner S, Brosch C, Lehmann A, Röhm $\mathrm{K}$, Mengistu A: Cardiopulmonary bypass priming using a high dose of a balanced hydroxyethyl starch versus an albumin-based priming strategy. Anesth Analg 2009;109:1752-1762. 